\title{
Comparison of Soil Testing Methods for Plant Available Phosphate
}

\author{
Myung Sook Kim*, Han Kang Kwak', Yoo Hak Kim, Seong Soo Kang, Myung Suk Gong, \\ Yong Seon Zhang, Hong Bae Yoon, and Chang Hoon Lee \\ Soil \& Fertilizer Management Division, National Academy of Agricultural Science, Suwon 441-707, Korea \\ ${ }^{1}$ Client Service Officer, Rural Development Administration, Suwon 441-707, Korea
}

(Received: May 29 2013, Accepted: June 7 2013)

\begin{abstract}
Most test methods for plant available soil phosphate are based on the extraction with a chemical solution. The objective of this study is to evaluate available phosphate of various tests at different soil phosphate levels. Two experiments were conducted as follows: i) Extracting capacities of soil phosphate tests - Mehlich III, Mehlich II, Bray I, Olsen, Kelowna, and Modified Lancaster(Mod. Lancaster) - were compared with that of Lancaster test for the soils collected from 32 paddy and 27 upland fields with various soil chemical properties. ii) Field trials on comparing to phosphate uptake by plant were accomplished by cultivating rice and com plants in the pots filled with the soils. Available phosphate of Lancaster test was significantly correlated with those of Mehlich III, Mehlich II, Bray I, Olsen, Kelowna, and Mod. Lancaster. In upland soils, available phosphates of all the tests were curvilinearly regressed with phosphate uptake by com. The determination coefficients $\left(R^{2}\right)$ of the regression equation between available phosphate in soils and phosphate uptake by plants were ranged from 0.861 (Mehlich III) to 0.741 (Olsen). In paddy soils, the available phosphate measured by Mehlich III and Lancaster was significantly correlated with phosphate uptake by rice. In conclusion, Lancaster and Mehlich III tests could be used for predicting available phosphate in upland and paddy soils.
\end{abstract}

Key words: Available phosphate, Colorimetry, ICP, Amount of phosphate uptake

Relationships between $\mathrm{P}_{2} \mathrm{O}_{5}$ uptake by com and rice and the soil available $\mathrm{P}_{2} \mathrm{O}_{5}$ determined with different soil test methods.

\begin{tabular}{lll}
\hline & \multicolumn{2}{c}{\left.${\text { Plant } \mathrm{P}_{2} \mathrm{O}_{5} \text { uptake }(\mathrm{g} \text { plant }}^{-1}\right)$} \\
\cline { 2 - 3 } Soil test & Corn & \multicolumn{1}{c}{ Rice } \\
\cline { 2 - 3 } & $\mathrm{R}^{2}$ & $\mathrm{R}^{2}$ \\
\hline Lancaster & $0.849^{* * *}$ & $0.557^{* *}$ \\
Mehlich III & $0.861^{* * *}$ & $0.546^{* *}$ \\
Bray I & $0.860^{* * *}$ & $0.462^{*}$ \\
Olsen & $0.741^{* * *}$ & $0.286^{\mathrm{ns}}$ \\
Mod. Lancaster & $0.858^{* * *}$ & $0.369^{*}$ \\
Kelowna & $0.786^{* * *}$ & $0.440^{*}$ \\
\hline
\end{tabular}

$*, * *$ and $* * *$; significant at $\mathrm{p}<0.05,0.01$, and 0.001 , respectively, ns; not significant.

*Corresponding author : Phone: +82312900329, Fax: +82312900208, Email: msk74@korea.kr

${ }^{\S}$ Acknowledgement: this study was conducted by support of NAAS research and development project(project number: PJ007434). 


\section{Introduction}

토양 중의 인산을 분석하는 목적은 작물이 인산을 유효 화하는 정도를 평가하고 토양에 적정한 인산을 시비하기 위 한 것이다.

토양 중의 인산은 크게 무기태와 유기태로 나뉘고 무기 태는 $\mathrm{Al}-\mathrm{P}, \mathrm{Fe}-\mathrm{P}, \mathrm{Ca}-\mathrm{P}$ 로 되어 있으며 유기태는 유기물과 결합된 형태로 되어 있다. 이렇게 결합되어 있는 성분이 토 양 중의 수용액으로 용해되어 나오고 작물이 이를 흡수하여 양분으로 이용한다. 이 때 작물이 흡수·이용하는 토양 중 의 인산의 양을 화학적 물질로 추출하여 정량하는 것이 유 효인산분석법이다 (Yoon, 1988).

기후와 모암 등에 따른 토양 특성과 사회적 여건 등으로 유효인산을 분석하는 방법은 나라마다 다르게 채택하여 사 용하고 있다. 국내에서는 작물시비를 위한 유효인산 분석법 으로 Lancaster법을, 국외에서는 Bray I (Bary and Kurtz, 1945), Olsen (Olsen and Sommers, 1982), Melich III(Mehlich, 1984), Kelowna (Van Lierop, 1988), Modified Lancaster (Mod. Lancaster)등을 사용하고 있다. Lancaster법은 국내 에서 1957년 미국의 미시시피 주립대학에서 도입하여 1960 년경부터 유효인산 분석법으로 적합한지를 검토한 후 사용 하여 왔다 (Yoon, 1988). 토양의 $\mathrm{pH}$ 에 따라 작물에 유효화 되는 정도가 달라 산성토양에서는 Bray I을, 석회암 토양에 서는 Olsen법으로 나누어 사용하였고, 분석방법이 발달하 면서 토양의 $\mathrm{pH}$ 가 높고 낮음에 상관없이 추출력이 일정하 고 인산 뿐만 아니라 다른 성분까지 분석하여 분석효율이 높은 추출방법으로 Melich III, Kelowna, Mod. Lancaster, Mehlich II 등이 개발되었다.

Melich III (Mehich, 1984)법은 산성과 염기성 토양의 인 산을 분석하는 데 효과적이며 $\mathrm{Ca}, \mathrm{Mg}, \mathrm{Mn}, \mathrm{K}, \mathrm{Na}, \mathrm{Cu}, \mathrm{Zn}$ 까지 추출할 수 있고 (Mehlich, 1984), 작물과의 상관성도 높다고 하였으며 (Mallarino, 2003), Yang et al. (2006)도 Lancaster법과 상관이 높고 방울토마토에서 작물과의 반응 이 좋다고 보고하였다. 인산이 환경의 부영영화의 원인이 되면서 Melich III를 미국의 국토자원관리국 (NRCS)에서 환 경으로 유출되는 인산을 정량하는 분석법 (Ketterings and Flock, 2005; Sharpley et al., 2003)으로 채택하여 점점 더 인산 분석법으로 사용하는 곳이 증가하고 있다.
Kelowna법은 산성과 염기성 토양에서 $\mathrm{P}, \mathrm{NO}_{3}-\mathrm{N}, \mathrm{K}$, $\mathrm{Mg}, \mathrm{Na}$ 을 동시에 추출할 목적으로 고안되었고 (Van Lieop, 1988) Mod. Lancaster법은 Lancaster법을 변경한 방법으로 $\mathrm{pH}$ 와 $\mathrm{CaCO}_{3}$ 함량 $\left(38 \mathrm{~g} \mathrm{~kg}^{-1}\right)$ 이 높은 토양에서도 인산의 추 출력이 높고 $\mathrm{K}, \mathrm{Ca}, \mathrm{Mg}, \mathrm{Mn}$ 을 동시에 분석할 수 있는 장점 이 있으며 작물과의 상관성이 높다고 하였다 (Cox, 2001, Jittanoonta, 1977).

Mehlich II (Mehlich, 1978)법은 국외에서는 $\mathrm{HCl}$ 성분으로 기기가 오염되어 Mehlich III로 대체되었고, Park and Ho (1998) 가 기존의 분석법인 Lancaster법과 비교하여 상관성도 높고 논 토양과 밭토양에서 작물과의 반응이 좋다고 보고하였다.

미국에서는 1990년대 초반부터 토양실험실에서 ICP (Inductively coupled plasma)의 사용이 급속하게 증가하였 다 (Munter, 1990; Jones, 1997; Mallarino, 2003). 그 이유 는 ICP를 사용하면 토양실험실의 분석절차를 간소화 할뿐 만 아니라 분석 시간과 경비를 절약할 수 있으며 농업인들 에게 토양의 분석결과를 신속하게 제공할 수 있는 장점이 있다. 2002년에 미국에서 ICP를 이용하는 Mehlich III 프로 그램 계획에 등록한 토양실험실은 $66 \%$ 에 달하고 있고 (Mallarino, 2003), 발색으로 측정하는 유효인산 분석방법 보다는 ICP로 측정하는 방법을 선호하고 있으며 작물별에 대한 토양 비옥도 적정범위가 설정되어 있어 ICP 사용은 지 속적으로 증가할 것이라고 하였다 (Mallarino, 2003).

본 연구의 목적은 아직 국내에서 적용성이 검토되지 않 은 분석법 (Mehlich III, Kelowna, Mod. Lancaster법)과 국 외에서 사용되고 있는 Bray I, Olsen, Mehlich II법들을 표 준분석법인 Lancaster 법과의 관계를 비교하고, 이러한 분석 방법들과 작물의 흡수량 및 수량과의 관계를 검토하여 국내 토양의 인산분석방법으로 적합한지를 평가하고자 하였다.

\section{Materials and Methods}

토양의 유효인산 방법간 비교 토양시료는 일반경작 지 (논 12 , 밭 12$)$, 시설재배지 (논 5 , 밭 5 ), 석회암토양 (논 5 , 밭 5), 고원지토양 (밭 5), 간척지 (논 5), 특이산성토 (논 5) 등의 화학적 특성이 다양한 논토양 32점, 밭토양 27점으로 총 59점 을 채취하였다. 공시토양의 화학성분별 평균함량과 범위는 Table 1 과 같다.

Table 1. Chemical properties of the studied soils.

\begin{tabular}{|c|c|c|c|c|c|c|c|}
\hline \multirow{2}{*}{$\begin{array}{l}\text { Chemical } \\
\text { properties }\end{array}$} & \multirow{2}{*}{$\mathrm{pH}$} & \multirow{2}{*}{$\mathrm{EC}$} & \multirow{2}{*}{$\mathrm{OM}$} & \multicolumn{4}{|c|}{ Exch. cation } \\
\hline & & & & K & $\mathrm{Ca}$ & $\mathrm{Mg}$ & $\mathrm{Na}$ \\
\hline & & $\mathrm{dS} \mathrm{m}^{-1}$ & $\mathrm{~g} \mathrm{~kg}^{-1}$ & \multicolumn{4}{|c|}{ 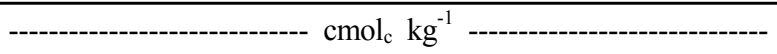 } \\
\hline Average & 6.1 & 0.44 & 38 & 0.79 & 6.5 & 2.1 & 0.73 \\
\hline Min & 4.4 & 0.03 & 3 & 0.12 & 0.31 & 0.1 & 0.02 \\
\hline Max & 8.5 & 4.54 & 238 & 5.16 & 23.8 & 8.9 & 21.57 \\
\hline
\end{tabular}


토양분석 방법 공시한 토양의 분석방법은 농촌진흥청 토양 화학분석방법 (NIAST, 2000)을, 유효인산 분석법 중 Lancaster법은 농촌진흥청 토양화학분석방법 (NIAST, 2000) 을, Mehlich III (Mehlich, 1984), Mehlich II (Mehlich, 1978), Bray I (NCR, 1998), Olsen (NIAST, 2000), Kelowna (Van Lieop, 1986), Mod. Lancaster (Cox, 2001)법은 Table 2 와 같이 추출하였고, $1-2-4$ 에 의한 Mo청법으로 발색시켜 Spectrophotometer (U-2000, HITACH) 혹은 ICP (Inductively Coupled Plasm, XMP, GBC)로 정량하였고, 점토함량 분석 은 비중계법으로 하였다.

\section{토양의 유효인산 함량과 옥수수 및 벼의 인산 흡수} 량과의 관계 옥수수를 재배한 밭토양에서는 일반경작지 3점, 유기물 함량이 $78 \mathrm{mg} \mathrm{kg}^{-1}$ 으로 높은 고원지 1점, $\mathrm{pH}$ 가 8.1로 높은 석회암 토양 1 점으로 모두 5 개의 토양을 채취하 였다. 공시토양의 화학성분별 평균함량과 범위는 Table 3 과 같으며, $\mathrm{pH}$ 는 5.1 8.1, 유기물 함량은 $5 \sim 78 \mathrm{~g} \mathrm{~kg}^{-1}$, 유효 인산 함량은 0 79 mg kg${ }^{-1}$, 점토함량이 $5.0 \sim 42.0 \%$ 로 매 우 다양하게 분포하였다.

실험방법은 $1 \mathrm{~m} \times 1 \mathrm{~m} \times 0.5 \mathrm{~m}$ 의 무저 pot에 토양 $500 \mathrm{~kg}$ 을 충진하고 시험구는 임의배치법 3 반복으로 하였다. 옥수 수는 사료용인 광평옥을 6 월 22일에 pot에 4주씩 이식하였
고 토양은 생육 30 일 후에 채취하였고, 옥수수 식물체는 정식 81 일 후에 지상부를 채취하여 분석하였다. 옥수수 시비량은 질소, 칼리는 토양검정 시비량으로 시용하였고 질소는 기비와 추비를 50:50으로 분시하였으며, 칼리는 전량 기비로 시용하였 다. 인산은 용과린을 토양검정시비량의 $0,0.5,2,3.5$ 배로 각 각 처리하였고, 석회는 중화량을 소석회로 시용하였다.

벼를 재배한 논토양 시료는 일반경작지 8점, 유기물 함량 이 $78 \mathrm{mg} \mathrm{kg}^{-1}$ 으로 높은 고원지 토양 1점, 석회암 토양 1점, 특이산성토양 1 점, 간척지 토양 1 점을 포함하여 모두 12점의 특성이 다양한 토양을 채취하였다. 공시토양은 $\mathrm{pH}$ 는 4.3 7.8 , 유기물 함량은 $5 \sim 73 \mathrm{~g} \mathrm{~kg}^{-1}$, 유효인산 함량은 $5 \sim 85 \mathrm{mg}$ $\mathrm{kg}^{-1}$ 으로 분포하였다. 실험방법은 $1 / 2000 \mathrm{a}$ pot에 토양 $10 \mathrm{~kg}$ 을 충진하고 임의배치법 4 반복으로 하였다. 벼는 추청벼를 6 월 5 일에 pot에 2 주씩 이식하였고 토양과 벼의 식물체 (지상 부)는 생육 54 일 후에 채취하여 분석하였다. 벼의 시비량은 질 소, 칼리는 토양검정 시비량으로 시용하였고 질소는 기비와 추비를 $50: 50$ 으로 분시하였으며, 칼리는 전량 기비로 시용하 였다. 인산은 용과린을 무비구, 토양검정시비량의 0.5 배, 1 배, 2 배로 각각 4 반복을 하였고, 석회는 중화량을 소석회로 시용 하였다. 간척지 토양은 석고를 석회포화도 $60 \%$ 조절량을 시용 하였고 $\mathrm{pH}$ 가 4.3 인 특이산성토양은 소석회 요구량을 시용하 여 벼 생육이 정상적으로 이루어지도록 하였다 (NIAST, 2006).

Table 2. Summary of the soil testing methods for available phosphate.

\begin{tabular}{|c|c|c|c|}
\hline Method & Extracting solution & $\begin{array}{l}\text { Soil:solution } \\
\text { ratio }\end{array}$ & $\begin{array}{c}\text { Time of } \\
\text { shaking (min) }\end{array}$ \\
\hline Lancaster & $\begin{array}{l}0.03 \mathrm{M} \mathrm{NH}_{4} \mathrm{~F}+10 \mathrm{M} \mathrm{Lactic} \text { acid }+17.6 \mathrm{M} \mathrm{HOAc}+0.05 \mathrm{M} \\
\left(\mathrm{NH}_{4}\right) 2 \mathrm{SO}_{4}+0.2 \mathrm{M} \mathrm{NaOH}\end{array}$ & $5 \mathrm{~g} / 20 \mathrm{ml}$ & 20 \\
\hline Melich II & $0.2 \mathrm{M} \mathrm{HOAc}+0.015 \mathrm{M} \mathrm{NH} \mathrm{H}_{4} \mathrm{~F}+0.012 \mathrm{M} \mathrm{HCl}+0.2 \mathrm{M} \mathrm{NH} \mathrm{NH}_{4}$ & $3 \mathrm{~g} / 25 \mathrm{ml}$ & 5 \\
\hline Melich III & $\begin{array}{l}0.2 \mathrm{M} \mathrm{HOAc}+0.015 \mathrm{M} \mathrm{NH} 4 \mathrm{~F}+0.25 \mathrm{M} \mathrm{NH}_{4} \mathrm{NO}_{3}+0.013 \mathrm{M} \mathrm{HNO}_{3}+ \\
0.001 \mathrm{M} \text { EDTA }\end{array}$ & $2.5 \mathrm{~g} / 25 \mathrm{ml}$ & 5 \\
\hline Kelowna & $0.25 \mathrm{M} \mathrm{HOAc}+0.015 \mathrm{M} \mathrm{NH} \mathrm{N}_{4} \mathrm{~F}$ & $2 \mathrm{~g} / 20 \mathrm{ml}$ & 5 \\
\hline Bray I & $0.03 \mathrm{M} \mathrm{NH} 4 \mathrm{~F}+0.025 \mathrm{M} \mathrm{HCl}$ & $2 \mathrm{~g} / 20 \mathrm{ml}$ & 30 \\
\hline Olsen & $0.5 \mathrm{M} \mathrm{NaHCO} 3(\mathrm{pH} 8.5)$ & $1 \mathrm{~g} / 20 \mathrm{ml}$ & 30 \\
\hline $\begin{array}{l}\text { Mod. } \\
\text { Lancaster }\end{array}$ & $\begin{array}{l}0.05 \mathrm{M} \mathrm{HCl} \text {, then } 1.58 \mathrm{M} \mathrm{HOAc}+0.125 \mathrm{M} \\
\mathrm{Malonic} \text { acid }+0.187 \mathrm{M} \text { Malic acid }+0.037 \mathrm{M} \mathrm{NH} \mathrm{NH}_{4}+0.01 \mathrm{M} \\
\mathrm{AlCl}_{3} \cdot 6 \mathrm{H}_{2} \mathrm{O}\end{array}$ & $5 \mathrm{~g} / 25 \mathrm{ml}$ & 15 \\
\hline
\end{tabular}

Table 3. Physico-chemical properties of soils under study.

\begin{tabular}{|c|c|c|c|c|c|c|c|c|c|c|}
\hline \multirow{2}{*}{ Soils } & \multirow{2}{*}{ Parameters } & \multirow{2}{*}{$\mathrm{pH}$} & \multirow{2}{*}{$\mathrm{EC}$} & \multirow{2}{*}{$\mathrm{OM}$} & \multirow{2}{*}{ Avail. $\mathrm{P}_{2} \mathrm{O}_{5}$} & \multicolumn{4}{|c|}{ Exch. cation } & \multirow[t]{2}{*}{ Clay content } \\
\hline & & & & & & K & $\mathrm{Ca}$ & $\mathrm{Mg}$ & $\mathrm{Na}$ & \\
\hline & & & $\mathrm{dS} \mathrm{m}^{-1}$ & $\mathrm{~g} \mathrm{~kg}^{-1}$ & $\mathrm{mg} \mathrm{kg}{ }^{-1}$ & \multicolumn{4}{|c|}{----- $\mathrm{cmol}_{\mathrm{c}} \mathrm{kg}^{-1}$} & $\%$ \\
\hline \multirow[t]{3}{*}{ Upland soils } & Average & 5.7 & 0.06 & 24 & 22 & 0.28 & 5.2 & 1.5 & 0.22 & 24.0 \\
\hline & Min & 4.9 & 0.01 & 5 & 0 & 0.14 & 0.8 & 0.3 & 0.05 & 5.0 \\
\hline & Max & 8.1 & 0.10 & 78 & 72 & 9.66 & 19.4 & 2.2 & 0.50 & 42.0 \\
\hline \multirow[t]{3}{*}{ Paddy soils } & Average & 6.3 & 1.45 & 18 & 37 & 1.24 & 7.1 & 4.4 & 3.23 & 26.0 \\
\hline & Min & 4.3 & 0.27 & 5 & 5 & 0.14 & 2.2 & 1.0 & 0.09 & 15.0 \\
\hline & Max & 7.8 & 5.77 & 73 & 85 & 9.66 & 25.0 & 18.2 & 29.85 & 44.0 \\
\hline
\end{tabular}


식물체 분석 방법 식물체 인산은 $\mathrm{H}_{2} \mathrm{SO}_{4}$ 와 $\mathrm{HClO}_{4}$ 를 사용 하여 식물체를 습식분해하여 ICP로 정량하였다 (NIAST, 2000).

\section{Results and Discussion}

토양의 유효인산 방법간 비교 여러 유효인산분석법 (Lancaster, Mehlich III, Mehlich II, Bray I, Olsen, Kelowna, Mod. Lancaster)으로 토양에서 추출하여 분석한 인산함량
은 Table 4 와 같다.

기존의 유효인산 분석법으로 사용하고 있는 Lancaster법 과 다른 분석방법간의 관계는 모두 통계적으로 고도로 유의 한 정의 상관 관계에 있었다 (Fig. 1). 이들의 결정계수 $\left(\mathrm{R}^{2}\right)$ 의 값은 Mehlich III $0.982^{* * *}$, Mehlich II $0.980^{* * *}$, Bray I $0.935^{* * *}$, Olsen $0.647^{* * * *}$, Kelowna 0.951*** Mod. Lancaster $0.768^{* * *}$ 로 Mehlich III, Mehlich II, Bray I, Kelowna는 Lancater법과 상관이 높았으나 Olsen, Mod. Lancater법은

Table 4. Average and range for $\mathrm{P}_{2} \mathrm{O}_{5}$ extracted with different chemical soil testing methods.

\begin{tabular}{|c|c|c|c|c|c|c|c|}
\hline Parameters & Lancaster & Mehlich III & Mehlich II & Kelowna & Bray I & Olsen & Mod. Lancaster \\
\hline & - & 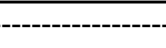 & 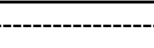 & $m g \mathrm{~kg}^{-1}$ & - & --- & ---- \\
\hline Mean & 398 & 569 & 403 & 441 & 509 & 244 & 709 \\
\hline Min & 5 & 8 & 7 & 1 & 2 & 5 & 23 \\
\hline Max & 2,676 & 3,641 & 3,198 & 3,113 & 3,476 & 939 & 6,944 \\
\hline
\end{tabular}
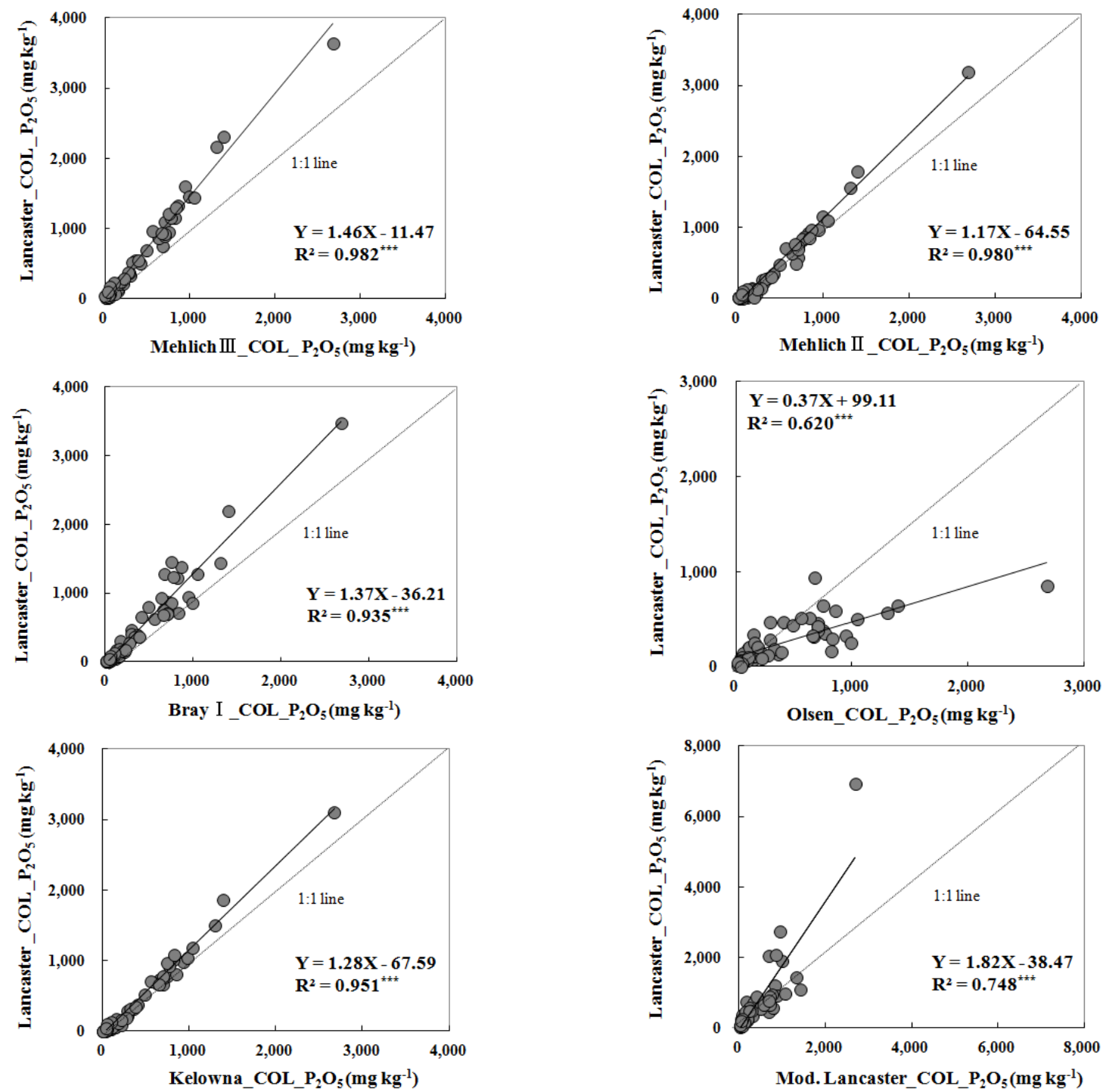

Fig. 1. Relationships between the $\mathrm{P}_{2} \mathrm{O}_{5}$ amounts extracted by Lancaster solution and six solutions (Mehlich III, Mehlich $\Pi$, Bray 1, Olsen, Kelowna, Mod. Lancaster). Determination of $\mathrm{P}_{2} \mathrm{O}_{5}$ extracted with seven tests. $\mathrm{COL}=\mathrm{P}_{2} \mathrm{O}_{5}$ detemination based on the colorimetry. ${ }^{* * *}$; significant at $\mathbf{p}<\mathbf{0 . 0 0 1}$. 
상대적으로 상관이 낮았다.

Park et al. (1992)은 논토양 18점과 밭토양 40점으로 Lancaster 법과 Mehlich III, Mehlich II법으로 추출되는 유효인산 사 이에 상관계수 $(\mathrm{r})$ 가 $0.965^{* * *}, 0.983^{* * *}$ 으로 통계적으로 고 도로 유의한 정의 상관에 있다고 보고하여 비슷한 결과가 나왔다. 그리고 Mallorino et al. (2005)도 59개의 Iowa 지 역의 분포하는 토양 78점을 이용한 국외에서 많이 사용하는 분석방법인 Bray I법과 Olsen법을 Mehlich III법과 비교한 결과 각각 결정계수가 $0.89^{* * *}, 0.97^{* * *}$ 로 추출되는 인산 함 량 사이의 고도로 유의한 직선유의한 상관을 얻었다고 하였 다. Gartley et al. (2002)도 Delaware 지역의 300점 토양 시료를 이용하여 Mehlich III법으로 추출되는 인산함량과 Bray I법으로 추출되는 인산함량들 간에 각각 결정계수의 값이 $0.97^{* *}$ 로 고도로 유의한 정의 상관을 얻었다고 하여 국 외의 여러 가지 기존의 많이 사용하는 유효인산 분석방법들 과 Mehlich III법간 상관이 높음을 알 수 있었다.
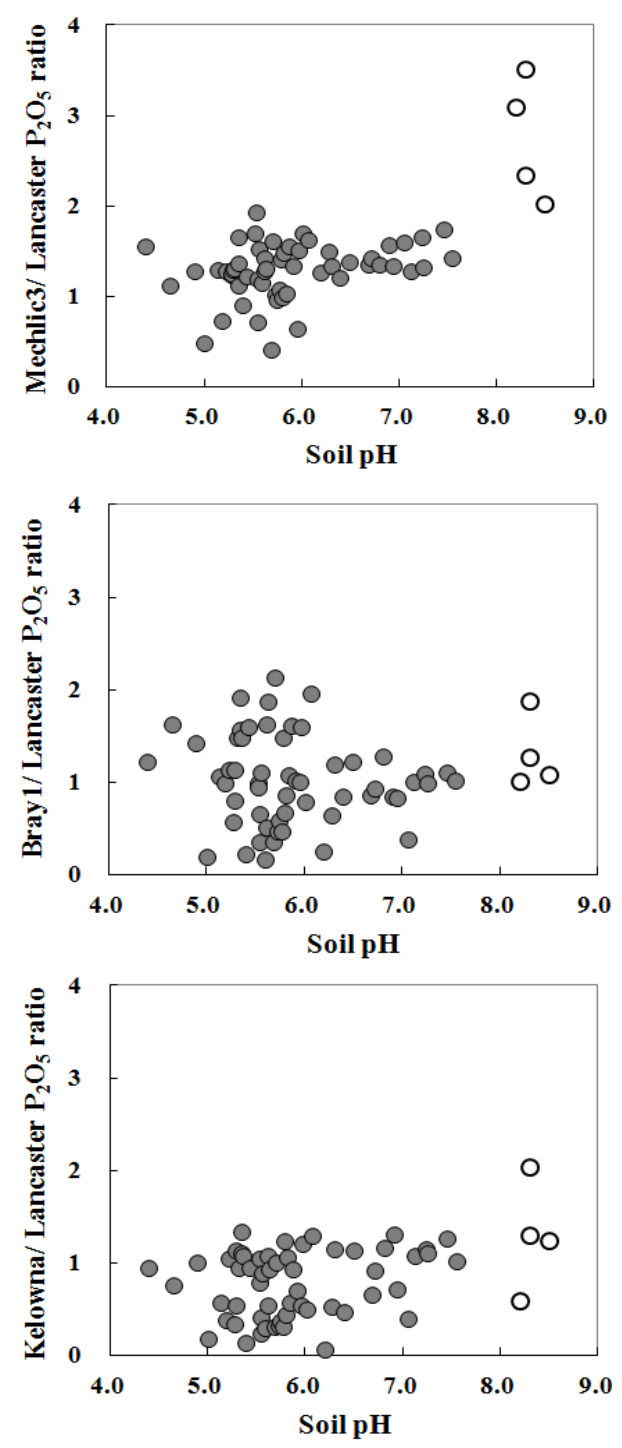

Mehlich III, Mehlich II, Bray I, Kelowna, Mod. Lancaster법과 Lancaster법으로 추출되는 인산함량과의 회 귀식에서 기울기가 1.17 1.93으로 Mehlich III, Mehlich II, Bray I, Kelowna, Mod. Lancaster법으로 추출되는 유효인 산의 함량이 Lancaster법보다 추출되는 인산의 양이 많았 다. 그러나 Olsen법은 기울기가 0.37로 유효인산 함량이 적 었다. 이것은 Mehlich III, Mehlich II, Bray I, Kelowna은 추출액 속에 $\mathrm{H}^{+}, \mathrm{F}^{-}$와 같은 유효인산 추출에 크게 관여하는 성분들이 조합되어 있고 Olsen법은 $\mathrm{HCO}_{3}{ }^{-}$만 있기 때문에 이들의 의한 차이로 판단된다.

Mehlich III, Mehlich II, Bray I, Olsen, Kelowna, Mod. Lancaster법을 Lancaster법의 인산함량에 대한 비율과 토 양 $\mathrm{pH}$ 와의 관계에서 Mehlich III/Lancaster의 비율은 토양 $\mathrm{pH} 4.0 \sim 8.0$ 에서는 최대 1.7 배에서 $\mathrm{pH} 8.0$ 이상에서는 3.5 배로 증가하였고, Mehlich II/Lancaster, Kelowna/Lancaster 의 비율도 토양 $\mathrm{pH} 4.0 \sim 8.0$ 에서 최대 1.3 배였던 것이 $\mathrm{pH}$
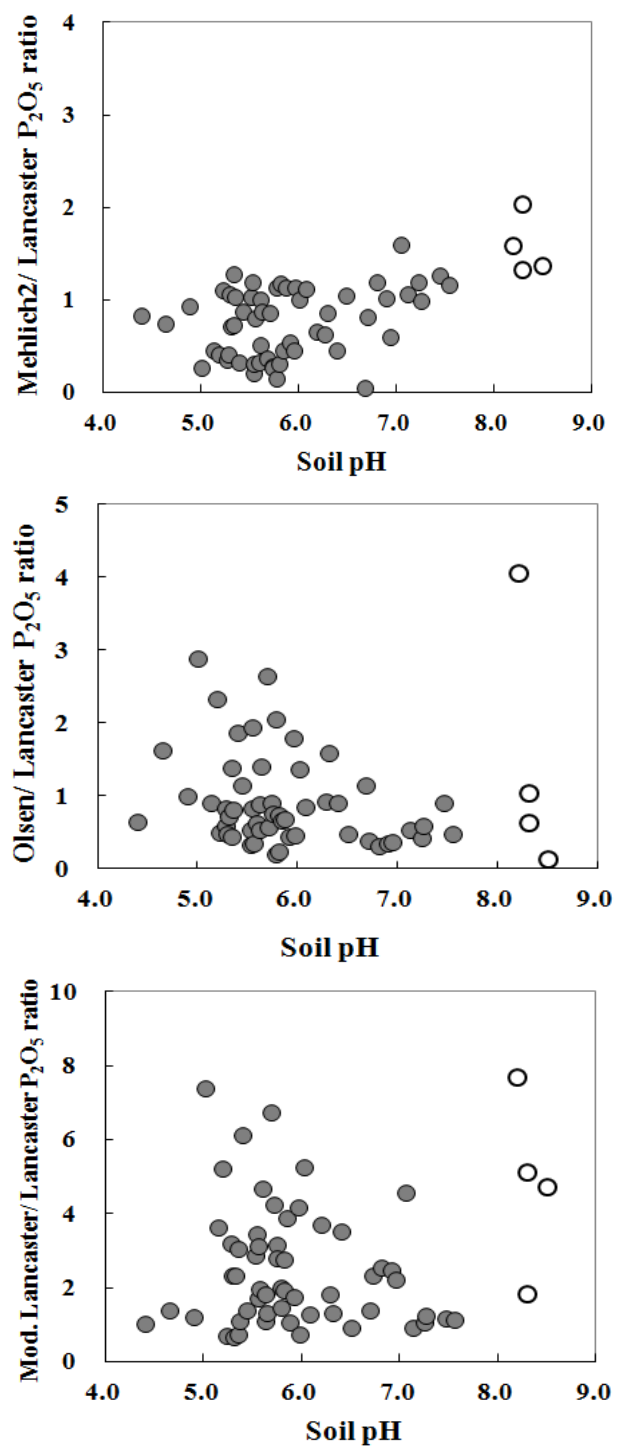

Fig. 2. Relationships between soil pH and ratios of $\mathrm{P}_{2} \mathrm{O}_{5}$ extracted by Mehlich III, Mehlich II, Bray I, Oslen, Kelowna, and Mod. Lancaster to Lancaster tests. 
8.0 이상에서는 최대 2.0배로 증가하였다. 그리고 Olsen/ Lancaster의 비율도 $\mathrm{pH} 8.0$ 이상의 추출비율이 증가하였 다. 그러나, 토양 Bary I/Lancaster와 Mod. Lancaster/ Lancaster의 비율은 일정하였다. 이로부터 Mehlich III, Mehlich II, Kelowna는 Lancaster법보다 $\mathrm{pH}$ 높은 토양에서 는 인산추출력이 증가하여 $\mathrm{pH}$ 의 중화에 따른 영향을 적었 다. Mallarino (2003)는 토양 pH가 7.8 (1:1 토양/증류수 비 율)이상, $\mathrm{CaCO}_{3}$ 과 $\mathrm{MgCO}_{3}$ 함량이 $36 \mathrm{~g} \mathrm{~kg}^{-1}$ 이상인 경우 Bray I법으로 추출한 인산함량에 영향을 주어 인산이 거의 추출이 안된다고 하였으나, 국내 토양은 $\mathrm{CaCO}_{3}$ 함량이 자 연토양에서도 $25.2 \mathrm{~g} \mathrm{~kg}^{-1}$ 으로 이보다 낮아 (Jung and Kim, 2006) 석회암 토양에서 인산이 일정수준 이상으로 추출이 된다고 볼 수 있었다 (Fig. 2).

Lancaster, Mehlich III, Mehlich II, Bray I, Kelowna, Mod. Lancaster법으로 추출한 여액을 Mo청법 (NIAST,
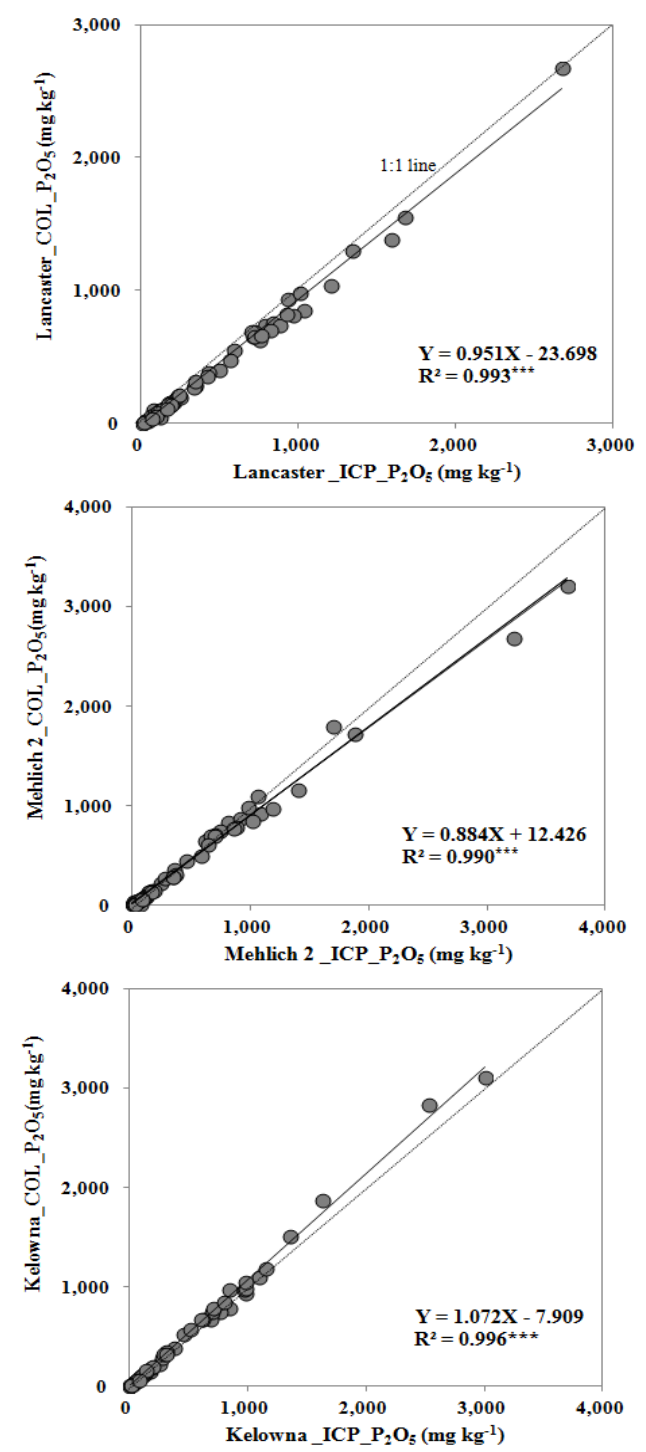

2000)에 의한 발색 측정치와 ICP로 측정한 값 사이에는 모 두 $0.990 \sim 0.998(\mathrm{P}<0.0001)$ 이상으로 유의한 정의 상관 관계가 있었다. 유효인산 함량을 발색으로 측정한 값보다 $\mathrm{ICP}$ 로 측정한 값이 높게 나왔는데 Lancaster법은 $26 \%$, Mehlich III법은 8\%, Mehlich II법은 25\%, Bary I법은 39\%, Kelowna법은 $24 \%$, Mod. Lancaster법은 $17 \%$ 가 많았다. 여 러 연구자는 발색으로 측정한 값보다 $\mathrm{ICP}$ 로 측정한 값이 $50 \%$ 더 높았다고 보고하였는데 (Hylander et al., 1995; Eckert and Watson, 1996; Nathan et al., 2002), 본 연구 와는 다소 차이가 있었는데, 토양특성 등에 따른 영향이라 생각된다.

이러한 이유는 유기태 인이 영향이라 하였고, 유기태 인 은 발색으로 측정할 때는 측정이 안되고, $\mathrm{ICP}$ 로 측정할 때 만 측정이 된다고 보고하였다 (Hylander et al., 1995; Eckert and Watson, 1996; Nathan et al., 2002). 토양유기물 함량
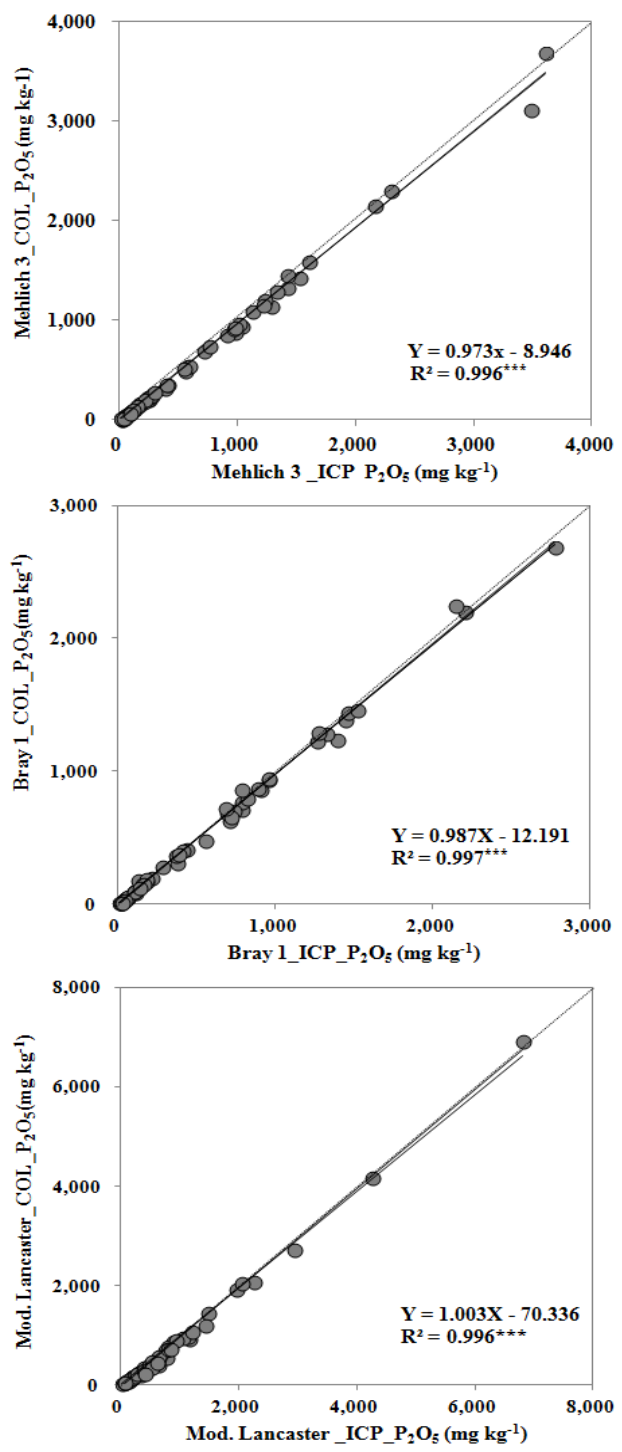

Fig. 3. Relationships of $\mathrm{P}_{2} \mathrm{O}_{5}$ concentrations between UV-Vis spectrometric and ICP measurements for the solutions extracted with different soil testing methods (Lancaster, Mehlich III, Mehlich II, BrayI, Kelowna, and Mod. Lancaster). ${ }^{* * *}$; significant at $p<$ 0.001. 
과 유효인산 발색측정치에 대한 ICP 측정치의 비율과의 관 계에서 토양유기물함량의 영향을 살펴본 결과 Lancaster, Mehlich III, Mehlich II, Bray I법으로 추출한 유효인산 함 량과 유기물 함량과 직선적인 상관관계가 있었고, 토양유기 물함량과 결함된 인산이 ICP 측정할 경우 영향을 미친다고 볼 수 있었다. 그리고 Lancaster, Mehlich II, Bray I법은 $\mathrm{ICP}$ 측정시 기기의 유로가 오염되었고, Olsen법은 $\mathrm{NaHCO}_{3}$ 에 의한 탄산가스의 생성으로 일정한 측정값을 얻기가 어려 웠으며, Mehlich III, Kelowna, Mod. Lancaster법등은 ICP 로 측정이 가능하여 분석효율을 높일 수 있는 방법으로 평 가되었다.

\section{토양 유효인산 함량과 작물의 인산 흡수량과의 관계} 밭과 논토양에서 Lancaster, Mehlich III, Bray I, Olsen, Kelowna, Mod. Lancaster법으로 추출한 유효인산 함량은
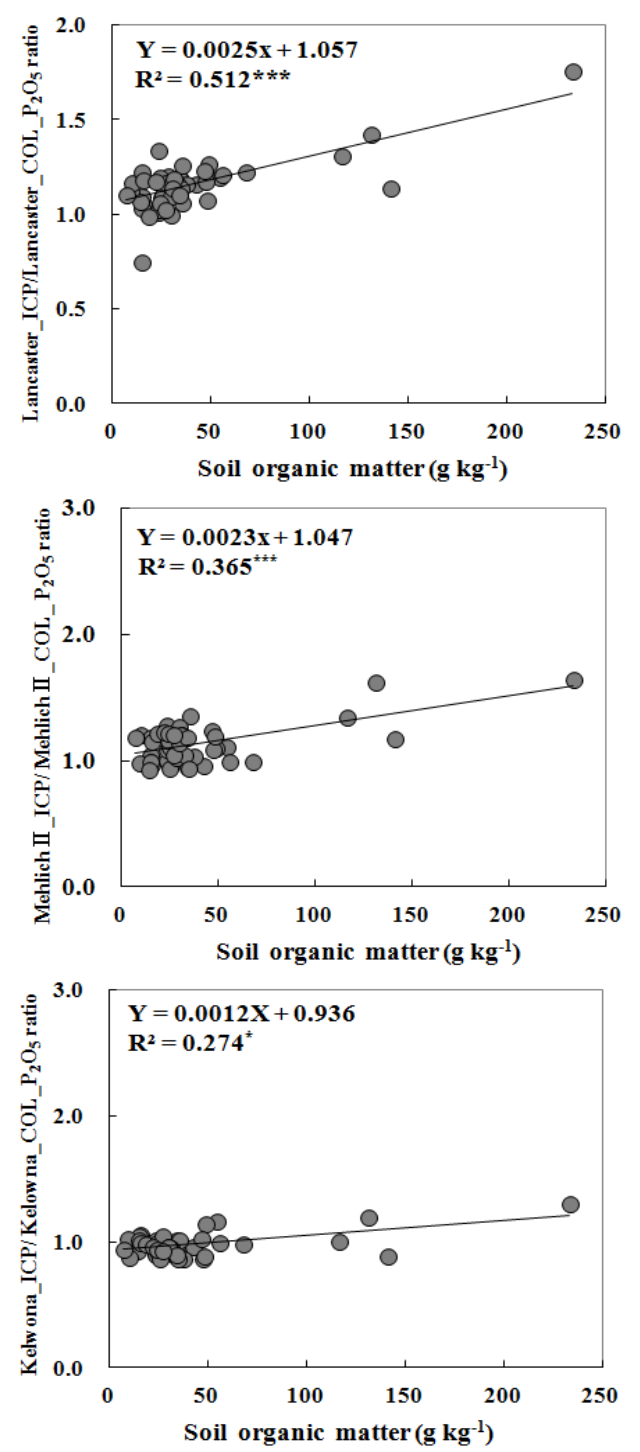

Table 5와 같다. 밭토양에서 Lancaster법보다 Mehlich III, Bray I, Mod. Lancaster법으로 추출한 인산함량은 17 $26 \%$ 가 많이 추출되었고, Kelowna법은 $7 \%$ 가 많이 추출되었으 며, Olsen법은 $22 \%$ 가 적게 추출되었다. 논토양에서는 Lancaster법보다 Mehlich III법이 52\%, Olsen법은 53\%, Mod. Lancaster은 69\%가 더 높게 추출이 되었고, Bray I, Kelowna법은 오히려 적게 추출되어 토양특성에 따라 차이 가 있었다.

밭토양의 Lancaster, Mehlich III, Bray I, Olsen, Kelowna, Mod. Lancaster로 추출한 유효인산 함량과 옥수수의 인산 흡수량과의 관계에서 모든 분석법에서 유의성이 있는 곡선 관계를 보였고, 이들의 결정계수 $\left(\mathrm{R}^{2}\right)$ 의 크기는 Melich III (0.861) > Bray I (0.860) $>$ Kelowna (0.858) $>$ Lancaster (0.849) $>$ Mod.Lancaster (0.786) $>$ Olsen (0.741)의 순으로 Melich III법이 가장 상관이 높았고 Olsen법이 가장 낮았다 (Fig.
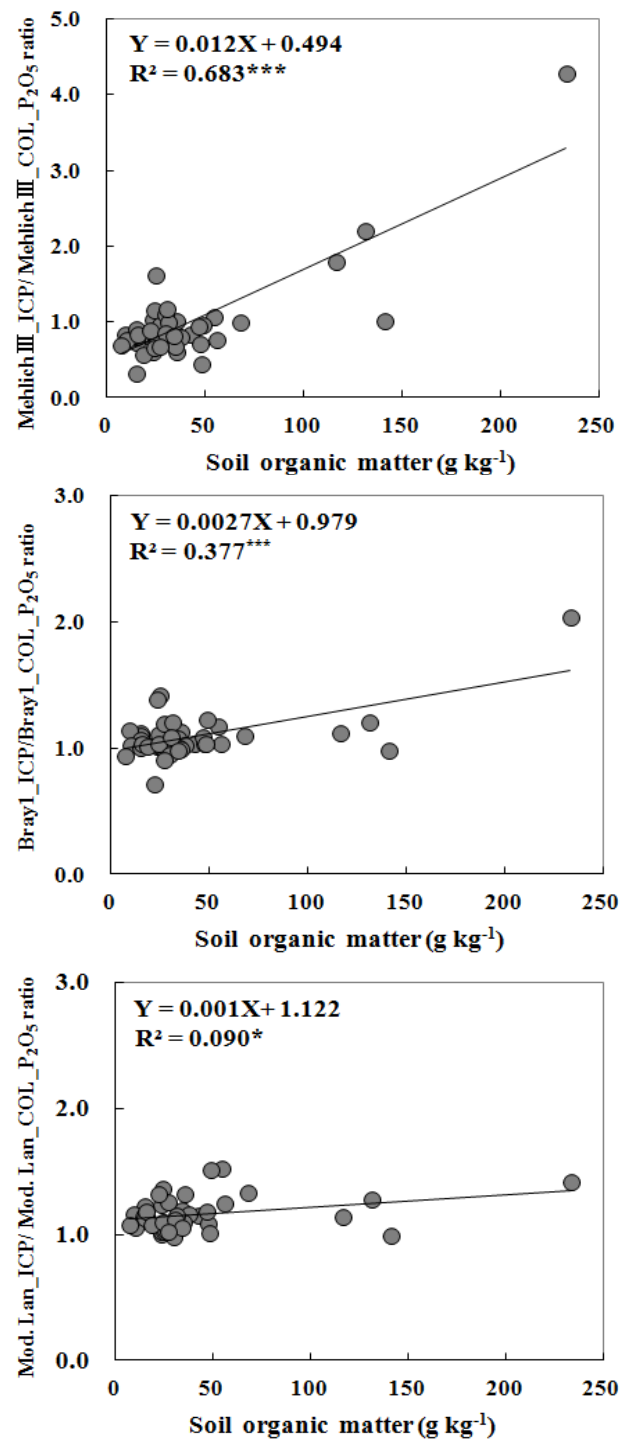

Fig. 4. Relationships between soil organic matter and soil $\mathrm{P}_{2} \mathrm{O}_{5}$ analyzed by Lancaster, Mehlich III, Mehlich II, Bray I, Kelowna, and Mod. Lancaster methods with ICP or UV-Vis spectrometric measurement. ${ }^{*}$ and ${ }^{* * *}$; significant at $p<0.05$ and 0.001 , respectively. 
Table 5. Mean and Range of $\mathrm{P}_{2} \mathrm{O}_{5}$ extracted with different soil testing methods for upland soils and paddy soils.

\begin{tabular}{|c|c|c|c|c|c|c|c|}
\hline Soils & Parameters & Lancaster & Melich III & Bray I & Olsen & Kelowna & Mod. Lancaster \\
\hline & & - & - & $n$ & & & - \\
\hline \multirow[t]{3}{*}{ Upland soils } & Mean & 367 & 457 & 431 & 287 & 392 & 462 \\
\hline & Min & 5 & 0 & 0 & 22 & 0 & 7 \\
\hline & Max & 1,442 & 1,918 & 1,936 & 841 & 1,368 & 1,481 \\
\hline \multirow[t]{3}{*}{ Paddy soils } & Mean & 32 & 46 & 26 & 49 & 26 & 54 \\
\hline & Min & 13 & 8 & 8 & 20 & 6 & 12 \\
\hline & Max & 54 & 90 & 67 & 68 & 50 & 104 \\
\hline
\end{tabular}
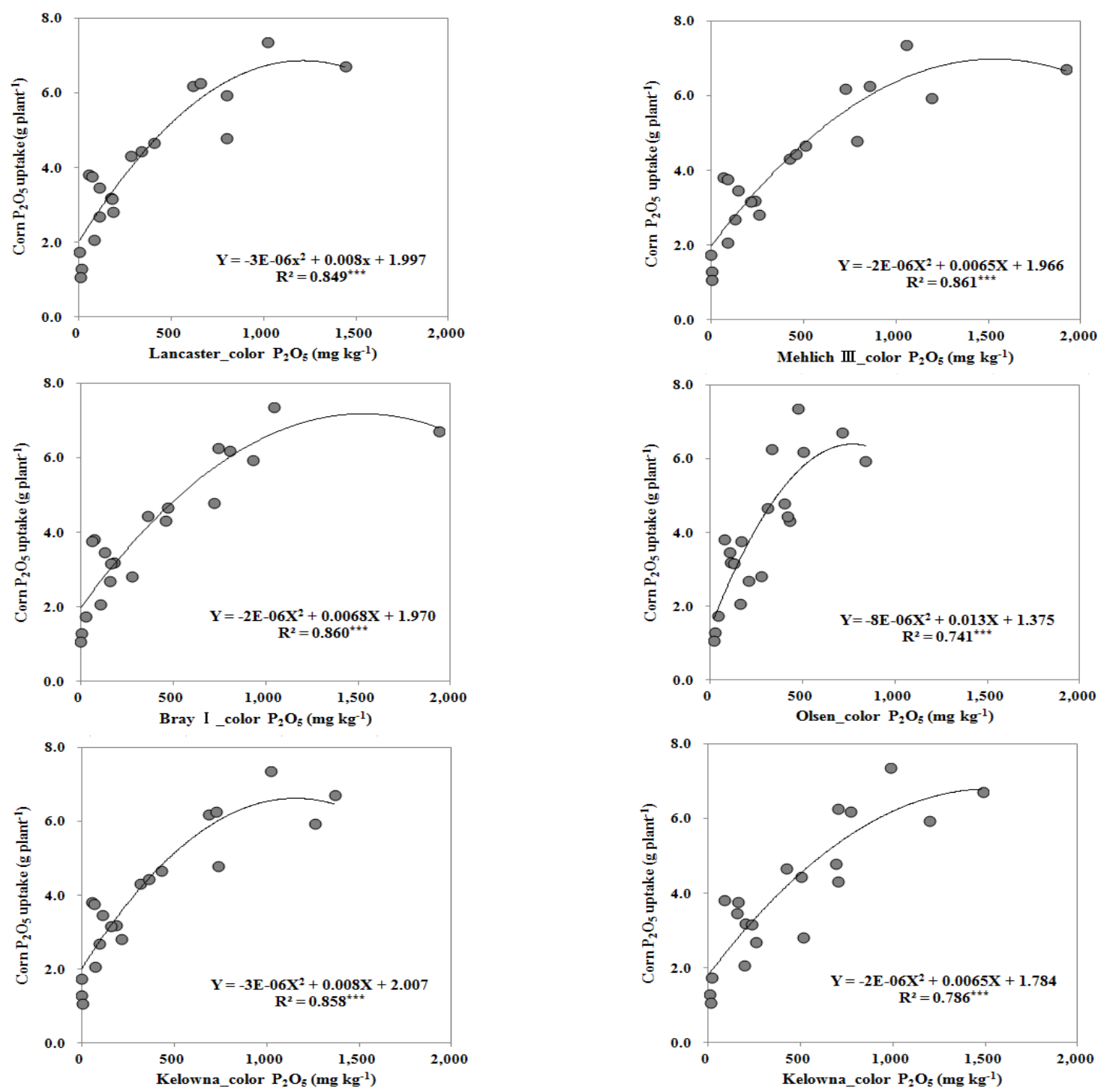

Fig. 5. Relationships between $\mathrm{P}_{2} \mathrm{O}_{5}$ uptake by com and available $\mathrm{P}_{2} \mathrm{O}_{5}$ in upland soils detemined by various extraction methods. ${ }^{* * *}$; significant at $p<0.001$.

5). Yoon et al. (1977)은 콩의 인산흡수량과 토양 유효인산 과의 관계에서, Park and Ho (1998)는 옥수수의 인산흡수량 과 토양 중 유효인산함량과의 관계에서 유의한 직선관계에 있다고 보고해 본 연구와는 다른 양상을 나타냈다. 이러한 이유는 작물 생육초기의 인산흡수 양상은 토양중의 인산함
량과 직선적인 관계가 있으나 생육후기로 갈수록 작물이 인 산을 흡수하는 모양이 곡선적으로 나타나기 (Kamprath and Watson, 1980) 때문에 본 실험은 작물생육 89일 후에 수확 한 식물체를, Park and Ho (1998)의 실험은 작물 생육 50일 에 수확한 것을 시료로 분석하였기 때문으로 판단된다. 
Table 6. Relationships between $\mathrm{P}_{2} \mathrm{O}_{5}$ uptake by rice and plant available $\mathrm{P}_{2} \mathrm{O}_{5}$ determination methods.

\begin{tabular}{lcc}
\hline \hline \multirow{2}{*}{ Soil tests } & & $\begin{array}{c}\text { Rice } \mathrm{P}_{2} \mathrm{O}_{5} \text { uptake } \\
(\mathrm{g} \text { plant }\end{array}$ \\
& Measurement & $\mathrm{R}^{2}$ \\
\cline { 3 - 3 } Lancaster & Colorimetry & $0.557^{* *}$ \\
& ICP & $0.566^{* *}$ \\
Mehlich III & Colorimetry & $0.546^{* *}$ \\
& ICP & $0.561^{* *}$ \\
Bray I & Colorimetry & $0.462^{*}$ \\
& ICP & $0.543^{* *}$ \\
Olsen & Colorimetry & $0.286^{\mathrm{ns}}$ \\
& ICP & \\
Mod. Lancaster & Colorimetry & $0.369^{*}$ \\
& ICP & $0.257^{\mathrm{ns}}$ \\
Kelowna & Colorimetry & $0.440^{*}$ \\
& ICP & $0.478^{*}$ \\
\hline
\end{tabular}

$*$ and $* * ;$ significant at $\mathrm{p}<0.05$ and $\mathrm{p}<0.01$, respectively, ns; not significant.

Lucero (1998)등은 가축분뇨를 넣은 토양 20개에서 Melich III와 Bray I으로 추출한 토양의 인산함량과 목초지 식물의 인산흡수량과의 관계에서 Melich III가 우수하였고, Bortolon et al. (2010)도 브라질 토양에서 콩과 옥수수의 인산 흡수 량과 Mehlich III로 추출한 유효인산 값과 상관이 높다고 하 였다.

논토양에서의 분석방법별로 추출하여 발색으로 측정한 유효인산 함량과 벼의 인산흡수량과의 관계는 Mehlich III, Lancaster법이 통계적으로 유의한 정의 상관관계에 있었으 나, Bray I, Olsen, Kelowna, Mod. Lancaster법은 상관관 계가 없었다 (Table 6). Park and Ho (1998)는 벼의 인산흡 수량과 Lancaster, Olsen, Bray I법으로 추출한 논토양의 유효인산 함량과의 관계에서 결정계수의 값이 Olsen법, Lancaster 법, Bray I법은 고도로 유의한 상관관계가 있으며 Lancaster, Bray I법이 모두 우수하다고 하여 본 연구와 다 른 결과가 나타났다. 이것은 인산함량이 $100 \mathrm{mg} \mathrm{kg}{ }^{-1}$ 이하 의 토양중의 인산함량을 대상으로 직선관계식을 적용하여 다른 결과가 도출되었다고 생각된다.

토양 중 유효인산 함량을 분석방법별로 추출한 여액을 $\mathrm{ICP}$ 로 측정한 값과 벼의 인산수량과 관계를 살펴본 결과 Mehlich III, Lancaster, Bray I법이 상관관계가 높았고, 그 값은 발색에 의한 Mehlich III, Lancaster법의 결정계수와 비슷하였으며, Mehlich III, Lancaster, Bray I으로 추출하 여 ICP로 측정한 인산의 함량이 벼의 수량을 잘 예측할 수 있음을 알 수 있었다.

\section{Conclusion}

토양의 유효인산 분석방법에 있어서 국내의 토양에 적용 성이 검토되지 않은 분석법 (Mehlich III, Kelowna, Mod. Lancaster 법)이 유효인산 분석법으로 적합한지를 알아본 결 과 국내의 표준분석법인 Lancaster법과 상관이 높으며 ICP 의 사용으로 분석효율이 좋은 Mehlich III법으로 추출한 분석 치는 작물과의 인산흡수량 및 수량과도 상관이 높아 국내 토 양의 유효인산 분석법으로 사용이 가능할 것으로 판단된다.

\section{References}

Bortolon, L., C. Gianello, and J.L. Kovar. 2011. Phosphorus availability to corn and soybean evaluated by three soil-test methods for southern Brazilian soils. 42:39-49.

Bray, R.H. and L.T. Kurtz. 1945. Determination of total organic and available forms of phosphorus in soil. Soil Science 59:39-45.

Cox. M.S. 2001. The Lancaster soil test method as an alternative to the Mehlich 3 soil test method. Socil Science 166(7): 484-489.

Gartley. K.L., J.T. Sims, C.T. Olsen, and P. Chu. 2002. Comparison of soil test extractants used in Mid-Atlantic Uinted States. Commun. Soil Sci. Plant Anal. 33(5\&6): 873-895.

Eckert, D.J. and M.E. Watson. 1996. Integrating the Mehlich-3 extractant into existing soil test interpretation schemes. Commun. Soil Sci. Plant Anal. 27:1237-1249.

Hylander, L.D., H.I. Svensson, and G. Siman. 1995. Comparison of different methods for determination of phosphorus in calcium chloride extracts for prediction of availability to plants. Commun. Soil Sci. Plant Anal. 26:913-925.

Jittanoonta, D. 1997. An evaluation of the new Mehlich soil test method of determining available phosphorus, potassium, calcium, magnesium, and manganese. M. S thesis. Mississippi State University.

Jones, J.B., Jr. 1997. Elemental analysis of soil extracts and plant tissue ash by plasma emission spectroscopy. Commun. Soil Sci. Plant Anal. 28:349-365.

Jung, W.K. and Y.H. Kim. 2006. Soil organic carbon determination for calcareous soils. Korean J. Soil Sci. Fert. 39(6):396-402.

Kamprath, E.J. and M.E. Watson. 1980. Conventional soil and tissue tests for assessing the phosphorus status of soils. In F.E. Khasawneh et al.(ed.) The role of phosphorus in agriculture, ASA, CSSA, and SSSA, Madison, WI.

Ketterings, Q.M. and M. Flock. 2005. Comparison of Bary-1 and Mehlich-3 tests in high phosphorus soils. Soil Science 170(3):212-219. 
Lucero, B.W. 1998. Comparison of Mehlich III- and Bray IExtractable phosphorus levels in a starr clay loam amended with poultry litter. Commun. Soil Sci. Plant Anal, 29(9\&10): 1133-1142.

Mallarino, A.P. 2003. Field calibration for corn of the Mehlich-3 soil phosphorus test with colorimetric and inductively coupled plasma emission spectroscopy determination methods. Soil Sci. Soc. Am. J. 68:1928-1934.

Mehlich, A. 1978. New Extraction for soil test evaluation of phosphorus, potassium, magnesium, Calcium, sodium, manganese and zinc, Commun. Soil Sci. Plant Anal. 9(6):477-492.

Mehlich, A. 1984. Mehlich III soil test extractant : A modification of Mehlich II extractant. Commun. Soil Sci. Plant Anal. 15(12):1409-1416.

Munter, R.C. 1990. Advances in soil testing and plant analysis analytical technology. Commun. Soil Sci. Plant Anal. 21:1831-1841.

Nathan, M.V. and Mallarino, A. Eliason, R and R. Miller. 2002. ICP vs colorimetric determination of Mehich III extractable phosphorus. Commun. Soil Sci. Plant Anal. 33:2432.

NIAST (National Institute of Agricultural Science and Technology). 2000. Methods of soil and plant analysis. National Institute of Agricultural Science and Technology, RDA, Suwon, Korea.

NIAST. 2006. Fertilizer Recommendation for crops (revision). National Institute of Agricultural Science and Technology, RDA, Suwon, Korea.

Olsen, S.R. and L.E. Sommers. 1982. Phosphorus soluble in sodium bicarbonate, pp 421-422. In : A. L. Page(ed.) American Society of Agronomy. Madison, WI.

Park, B.G. and J.H. Yoon. 1992. Study on the simplified extraction methods for the analysis of available nutrients in the soil. Res, Rept. RDA(S\&F). 34(2):43-27.

Park, B.G. and A.H. Ho. 1998. Comparison of several methods for the determination of available phosphorus in the soils for corn and rice. Korean J. Soil Sci. Fert. 31(1):1-8.

Reyes, E.D., J.G. Davide, L.G. Orara, and R.A. Calixihan. 1962. Nitrogen, phosphorus and potassium uptake by a lowland rice variety at different stages of growth. Philippine Agriculturist 46(1):7-19.

Sharpley, A.N., J.L. Weld, D.B. Beegle, P.J.A. Kleinman, W.J. Gburek, P.A. Moore, Jr. and G. Mullings. 2003. Development of phosphorus indices for nutrient management plannings strategies in the United States. Journal of Soil and Water Conservation 58(3):137-152.

Van Lierop, W. 1988. Determination fo available phosphorus in acid and calcareous soils with the Kelowna multi-element extract. Soil Science 88:284-291.

Yang, W.S., S.S. Kang, K.I. Kim, and S.D. Hong. 2006. Comparison of determination methods for available-P in soil of plastic film house. Korean J. Soil Sci. Fert. 39(3):163-172. Yoon, J.H., C.W. Shin, I.S. Ryu, and C.W. Hong. 1977. Comparison of several mehtods for the evaluation of available soil P in upland soils. Korean J. Soil Sci. Fert. 10(4):219-224. Yoon, J.H. 1988. Soil chemistry. 21(S.I):52-70. 